\title{
Elemental Enrichment of Foods: Essentiality and Toxicity
}

\author{
Juliana Naozuka* \\ Universidade Federal de São Paulo, Chemistry Department, Brazil
}

Submission: November 20, 2017; Published: January 06, 2018

*Corresponding author: Juliana Naozuka, Universidade Federal de São Paulo, Chemistry Department, 275 Prof. Artur Riedel St. 09972270, Diadema, Sao Paulo, Brazil, Email: j.naozuka@unifesp.br

\begin{abstract}
Enrichment foods with essential elements are one way to supply micronutrient deficiency. For this, the fortified fertilizing of the soils is a promising strategy. However, the enrichment through appropriate cultivation should be seen beyond the need to minimize nutritional deficiencies, since that it can also be applied in the resolution of environmental problems, aiming at reducing toxicity by heavy metals in food. In both studies it is necessary to evaluate the interactions between the different elements during absorption and translocation. Additionally, it is important to point out that the necessity to know the elemental species capable of being absorbed and used by plants and mushrooms in their metabolism, as well as species formed after enrichment, since that is necessary to evaluate if these fortified foods have the same chemical characteristics of those formed when the food is grown under natural soil conditions and free of toxic metals.
\end{abstract}

\section{Introduction}

The ideal food should contain all the macro and micro nutrients that the human being needs. However, certain nutrients, mainly microelements, are not always available to the population and in all foods. In function of this, food education, drug supplementation or fortification/enrichment foods have been recommended to balance and ensure healthy life [1]. Food enrichment is a way of supplying micronutrient deficiency, being a recommended intervention alternative, especially to places where high prevalence's are found [1]. In processed foods, it has been shown to be a very efficient way of reducing the risk of micronutrient deficiencies in the population. Dairy products and cereals are considered the main vehicles to be fortified, and have several advantages because they are widely used and well adapted to the diet of children [1].

Another way of enrichment is to cultivate foods (fruits, vegetables, nuts, mushrooms, cereals, beans and rice) in soils or medium previously treated with the interest micronutrients. The most used enrichment processes are: addition of the element in the soil (salts of the element), foliar treatment with solution, immersion of the seeds in solution before planting, hydroponic seed cultivation in solution of the element [1,24]. In this scenario, the sprouts can be a good alternative in the obtainment of enriched food. Multiple food enrichment is economically feasible when compared to the addition of a single nutrient and is successfully applied in developing countries [1]. Although economically feasible, for the success of multiple enrichment it is essential to know the possible interactions and competitions between the elements.

In plants, the low accumulation of an element in the stem in the presence of another element may be the result of different stages of interaction, such as uptake by root, translocation from root to xylem epidermis or xylem translocation and transport of xylem to leaf cells [5]. Studies have shown that the similarity between the chemical properties of bivalent cations can explain the uptake of metals by plants, including competition between the elements by protein carriers of root absorption $[6,7]$.

The strategy of enrichment through appropriate cultivation must be seen beyond the need to overcome nutritional deficiencies or to guarantee the presence of essential elements in the food, since it can also be applied in solving environmental problems. Plants and fungi have the ability to absorb, translocate and accumulate toxic metals in their tissues. Using enrichment procedures for the purpose of reducing heavy metal toxicity in food requires studies of interactions between the different elements during absorption and translocation. The decrease in the uptake of an element in the presence of another element in the plant or fungi culture medium is evidence of competition or an inhibitory effect on the transporters [6]. In Alyssym inflatum the presence of $\mathrm{Ni}$ in 
the soil strongly interferes with the translocation of Fe by its roots, while absorption of Ca decreases Ni toxicity [6].

In this way, it is evident that for the success of enrichment procedures, aiming at nutritional improvement or minimization/elimination of toxicity problem s by heavy metals, studies of competition between elements are fundamental importance. In addition, it is important to highlight the need to know the elemental species capable of being absorbed and used by plants and fungi in their metabolism, as well as species formed after enrichment, and it is necessary to evaluate if these fortified foods have the same chemical characteristics of those produced when the food is grown under natural soil conditions and free of toxic metals.

Therefore, for the enrichment success studies of elemental chemical speciation are imperative, because it allows identifying and/or determining the chemical forms in which the element is found in a given matrix [8]. Additionally, the determination of the different chemical forms of the elements can result in information about the absorption of the elements and subsequently their use to perform the physiological functions, that is, the chemical speciation can estimate the bioavailability and bio-accessibility of the nutrient [8].

In summary, studies of chemical speciation, bioaccessibility and bioavailability promote knowledge capable of assisting in the evolution and improvement of information regarding the conscious use of functional foods, since these consist of a source that besides presenting its nutritional functions as energy source and substrate for the formation of cells and tissues, also has in its composition one or more chemical species capable of acting to modulate the metabolic processes of people preventing the early onset of degenerative diseases, leading to increased longevity [9].

\section{Elemental Enrichment: Adzuki Beans Sprouts}

Beans are a typical crop of tropical and subtropical climate. In the human nutrition, beans are an important leguminous source of proteins [10]. The Vigna comprises about 160 species, among them is the adzuki or azuki bean (Vigna angularis), which is produced and consumed mainly in Asia [10].

Bean sprouts are used in soups and salads in various Asian countries [11]. Additionally, they are appreciated for their taste and value nutritional and medicinal [11]. It is called germinated food or sprouts, in which the seed is stimulated after contact with external factors, such as water, air and heat, resulting in growth. After the germination process, the seeds will form the stem and the leaves, originating the sprouts. Additionally, the germination process also improves nutritional factors, increasing protein digestibility, fiber content and availability of essential elements and reducing antinutritional factors (such as trypsin inhibitors, phenolic compounds and nitrate) [9]. The elemental availability can be affected during germination, because the enzymes present in the seed, among them phytase, are rapidly activated by simple hydration, consequently, the hydrolyzed phytic acid allows the release of metal ions, making them more available [9].

There is a growing search for alternatives that adapt to the new concept of healthy food and free of pesticides that can cause damage to health and the environment [12]. Therefore, the production of edible sprouts is a segment that has been highlighting in human nutrition, being a technique widely used in the United States, Europe and Asia, which can be implanted even in the urban environment [12]. Urban agriculture is an initiative that has grown in many cities around the world, generating the possibility to improve the living conditions of the population and favors the search for foods free of pesticides. These healthy foods add good sensory attributes and low cost, and are increasingly accepted by the demanding population looking for products that can benefit them in some way from their bioactive properties [12].

Mung bean, commonly called moyashi, is the species most commonly used for the production of sprouts. However, more than 30 species of plants, mainly olives (broccoli, radish, onion, mustard) and legumes (azuki beans, alfalfa, clover, lentils) are used for this purpose. Sprouts are highly nutritious foods, whose production is rapid, about 4 to 6 days, and can be performed at any time of the year, without the need for soil, fertilizers, pesticides and direct sunlight In this way, the sprouts stand out because they are food free of agricultural defenses that is a segment that deserves attention in the human diet and grows considerably in several countries. Additionally, this food is totally natural, uses only the reserves stored in the seeds to germinate and reach the size to be consumed, besides being good sources of minerals, vitamins, proteins, and have low caloric content $[2,4,5]$. Furthermore, it is possible to enrich the sprouts with essential elements, adding the nutrient to the culture medium.

In relation to the cultivation under conditions of soils enriched with essential elements, recent studies have shown that the enrichment with the increase of the productivity, with the increase of the biomass or produced grain, of $43 \%$ of canola seeds, $14 \%$ of lettuce and $40 \%$ of potatoes. Seeds have become more resistant to variations in the medium, mainly due to the increase of the antioxidant capacity promoted by the organic compounds of Se. Therefore, in addition to the nutritional appeal generated by the production of foods rich in Fe and Se, there is also a need to consider the economic aspects with increasing productivity [13].

Enrichment studies of adzuki beans sprouts with Fe and Se have been performed [2,3]. For Fe enrichment [2], it was added to culture medium FeIII- ethylenediaminetetraacetic acid (FeIII-EDTA). The enrichment via FeIII- Fe with albumins (141\%), globulins (180\%), and glutelins (93\%). In the bioaccessibility assays, Fe was $83 \%$ can be fixed in plant roots because of various chemical reactions and due to the low 
mobility in plant tissue.

Evaluation of Se accumulation, uptake and translocation in plants in different culture media (selenite or selenate) was verified [3]. Translocation of Se was higher using selenate for enrichment, resulting in sprouts with $890 \%$ higher Se concentration than in the selenite-enriched medium. The percentage of Se associated to proteins (albumins, globulins, prolamins and glutelins) was 54\% using selenite, while with selenate, it was only $19 \%$. In the bioaccessibility studies, Se was $100 \%$ bioaccessible in both enriched medium. It is important to point out that the inclusion of adzuki bean sprouts enriched with Se in the daily diet presents a relevant and potential contribution to the daily intake recommendations of Se.

The inclusion of adzuki bean sprouts enriched with Fe and Se in the daily diet is a promising way to fill the daily intake recommendations of these essential elements. The consumption of enriched sprouts is a good alternative combination with products that contribute to the dissemination of healthy and functional foods.

\section{Remediation $\mathrm{x}$ enrichment: mushrooms}

There are approximately 10,000 known mushroom species, of which 50 are toxic, 50-200 are used in medicinal practices and 700 are edible, among the edible species only 25 are commercially grown $[14,15]$. The consumption of edible mushrooms is in rapid expansion due to its refined taste, high nutritional value and medicinal properties [14,15]. The Pleurotus has aroused great interest by medical and scientific community, because these mushrooms have high nutritional value, are good sources of proteins, carbohydrates, vitamins, calcium and iron, besides presenting low cost and important medicinal properties [15]. The products derived from Pleurotus mushrooms have anti tumorigenic properties, modulate cholesterol levels, prevent platelet aggregation in the arteries avoiding cardiovascular diseases, combat the hepatitis $\mathrm{C}$ virus, and exert antioxidant and antibacterial properties [16].

The shimeji (Pleurotus ostreatus) is one of the most widespread mushrooms in the world, commonly consumed fresh or dehydrated, source of lysine and vitamin B1 $[17,18]$. The salmon mushroom or hiratake salmon (Pleurotus djamor) is consumed raw, in small quantities, marinated with seasonings, adorning salads or dishes with seafood and presents high antioxidant potential $[17,18]$. Therefore, when present in food supply any nutritional deficiencies, besides being possible to enrich them with essential elements, as for example with Se [15].

One of the major public health problems in developing countries is Se deficiency, which is related to increased blood plasma cholesterol, liver dysfunctions and Kesham's disease, which affects more than 10 million Chinese. [3] Beside this, studies indicated that $\mathrm{Se}$ is able to protect living beings against heavy metal toxicity by inhibiting the action of these metals through less harmful chemical species that are formed and changes in metabolic processes $[19,20]$. Mushrooms, due to their composition $(1-20 \mathrm{~g} / \mathrm{g}$ ) and being bioaccumulators, have been the subject of studies aimed at total determination, speciation and their enrichment with this element $[15,21,22]$. In the enrichment of this food with Se, it must be assessed whether the enriched food has the same characteristics and chemical species that would be absorbed in natural conditions of cultivation.

Mushrooms are also of interest in research involving bioremediation, since they have a high capacity to accumulate toxic elements, such as cadmium (Cd), mercury ( $\mathrm{Hg}$ ) and lead $(\mathrm{Pb})$ [23-25]. The presence of these toxic elements in mushrooms may be related to the cultivation substrate itself, environmental contamination and species characteristics (age of the micelle and genetic factors) [26].

In summary, mushrooms as being accumulators of essential and toxic elements can be used to supply Population prevalences and bioremediate anthropogenically contaminated sites. However, in cases of bioremediation it is also essential that mushrooms with high concentration of toxic elements be properly treated. Studies have shown that Se has the ability to remediate the contamination of mushrooms $[27,28]$. Competition between the elements can lead to the minimization and / or elimination of toxic elements. In living organisms and foods it has already been shown that there is a competition between Se and Hg [19,29-32].

Wang et al. [33] evaluated the protective effect of Se against $\mathrm{Hg}$ toxicity in marine mammalian kidney cells and after culturing the cells exposed to different concentrations of $\mathrm{HgCl}_{2}$ and a pretreatment with $\mathrm{Na}_{2} \mathrm{SeO}_{3}$, the protective effect against the toxicity of $\mathrm{Hg}$, however, the coexistence of Se and $\mathrm{Hg}$ in the culture medium was essential for the protective effect of $\mathrm{Na}_{2} \mathrm{SeO}_{3}$ against the toxicity of $\mathrm{HgCl}_{2}$ in renal cells, indicating an antagonistic effect on the absorption of these elements. In tomato and radish cultivation in the greenhouse system, plants irrigated with $\mathrm{HgCl}_{2}$ accumulated less $\mathrm{Hg}$ after the addition of solutions of selenite or selenate $(0.5-6.0 \mathrm{mg} / \mathrm{L})$ to the soil, with the formation of HgSe in situ because of the reduction of $\mathrm{Hg}$ accumulation [34,35]. The mechanisms of absorption and chemical speciation for the antagonistic effect between $\mathrm{Hg}$ and S Include the formation of methylmercurySe compounds, the demethylation of MHg (methylmercury), the formation of inorganic $\mathrm{Hg}$-Se and the redistribution of Inorganic Hg in the presence of Se [36,37]. However, There are no studies, especially of chemical speciation, for Pleurotus edible varieties, such as hiratake salmon.

Studies on the role of Se in the remediation of $\mathrm{Cd}$ and $\mathrm{Pb}$ are scarce in the literature. In Pleurotus micelles, the Protective role of Se against $\mathrm{Cd}$ toxicity was verified, due to the lower incorporation of the toxic metal and the lettuce and Chinese cabbage with $\mathrm{Zn}$ and Se restricts the accumulation of $\mathrm{Pb}$ and $\mathrm{Cd}$ 
and increases absorption that for mushrooms, the antagonism between $\mathrm{Se}$ and $\mathrm{Cd}$ or $\mathrm{Pb}$ has not yet been studied.

Although there are studies in the literature evidencing the ability to enrich mushrooms with Se and also to use this element to remedy the toxicity of $\mathrm{Cd}, \mathrm{Hg}$ and $\mathrm{Pb}$, the competitions between the different species of Se with the toxic metals, as well as the species formed after enrichment or remediation still require further study. In addition, some of the Pleurotus varieties do not have enrichment, competition, and remediation information.

Therefore, information about the distribution, competition, and chemical form in which the elements are found in a particular matrix are important and may result in information on the absorption, bioavailability, benefits, and, eventually, health risks of ingestion.

Finally, chemical speciation studies, together with the evaluation of the synergistic relationship between essential and toxic elements, promote knowledge capable of assisting in the evolution and improvement of information regarding the conscious use of edible mushrooms as functional foods, bio indicators and pollution bio remediation [38-41].

\section{Acknowledgments}

The author is grateful to Fundação de Amparo à Pesquisa do Estado de São Paulo/FAPESP (2015/15510-0). Compliance with Ethics Requirements Juliana Naozuka declares that she has no conflict of interest. This article does not contain any studies with human or animal subjects.

\section{References}

1. Ahmed A, Anjum FM, Ur Rehman S, Randhawa MA, Farooq U (2008) Bioavailability of calcium, iron and zinc fortified whole wheat flour chapatti. Plant Foods Hum Nutr 63(1): 7-13.

2. Oliveira AP, Naozuka J (2017) Effects of Iron Enrichment of Adzuki Bean (Vigna angularis) Sprouts on Elemental Translocation, Concentrations of Proteins, Distribution of Fe-Metalloproteins and Fe Bioaccessibility. Journal Brazilian of Chemical Society 28: 1937-1946.

3. Oliveira AP, Nomura CS, Naozuka J (2017) "Evaluation of selenium enrichment of adzuki bean (Vigna angularis) sprouts: Translocation, bio-accessibility and Se-protein speciation." Microchemical Journal 134: $19-26$

4. Smrkolj P, Osvald M, Osvald J, Stiblj V (2007) Selenium uptake and species distribution in selenium-enriched bean (Phaseolus vulgaris L.) seeds obtained by two different cultivations. European Food Research Technology 225(2): 233-237.

5. Fernández V, Del Rio V, Lumariño L, Igartua E, Abadia J, et al. (2008) "Foliar fertilization of peach (Prunus pérsica (L.) Batsch) with different iron formulations: Effects on re-greening iron concentration and mineral composition in treated and untreated leaf surfaces." Scientia Horticulturae 117: 241-245.

6. Ghaderian SM, Ghasemi R, Hajihashemi F (2015) “Interaction of nickel and manganese in uptake, translocation and accumulation by the nickel-hyperaccumulator plant, Alyssum bracteatum (Brassicaceae)." Australian Journal of Botany 63(2): 47-55.

7. Boyd RS, Martens SN (1998) "The significance of metal hyper accumulation for biotic interactions" Chemoecology 8(1): 1-7.
8. Miranda MZ, El-Dash A (2002) "Farinha integral de trigo germinado. 3. Características nutricionais e estabilidade ao armazenamento." Ciência e Tecnologia dos Alimentos 22(3): 216-223.

9. Ribeiro MLL, Ida EI, Oliveira MCN (1999) "Efeito da germinação de soja cv. br-13 e paraná sobre ácido fítico, fósforo total e inibidores de tripsina." Pesquisa Agropecuária Brasileira 34(1): 31-36.

10. Steele WM, Mehra KL (1980) Structure evolution, and adaptation to farming systems and environments in Vigna. In: Summerfield, RJ; Bunting, AH (Eds.), Advances in Legume Science. Royal Botanic Gardens, Kew, UK, pp. 393-404.

11. In PY, Lai HM (2006) "Bioactive compounds in legumes and their germinated products." J Agric Food Chem 54(11): 3807-3814.

12. Bellenda B (2005) "Huertasen Montevideo: agriculturaurbana a la uruguaya”. LEISA-Revista de Agroecologia 21: 29-32.

13. Ekanayake L, Thavarajah D, Vial E, Schatz B, McGee R, et al. (2015) "Selenium fertilization on lentil (Lens culinaris Medikus) grain yield, seed selenium concentration and antioxidant activity." Field Crops Research 177: 9-14.

14. Mattila P, Könkö K, Eurola M, Pihlava JM, Astola J, et al. (2001) “Contents of vitamins, mineral elements, and some phenolic compounds in cultivated mushrooms." J Agric Food Chem 49(5): 2343-2348.

15. da Silva MC, Naozuka J, da Luz JMR, de Assunção LS, Oliveira PV, et al (2012) "Enrichment of Pleurotusostreatus mushrooms with selenium in coffee husks." Food Chem 131(2): 558-563.

16. Sarangi I, Ghosh D, Bhutia SK, Mallick SK, Maiti TK (2006) "Anti-tumor and immune modulating effects of Pleurotusostreatus mycelia-derived proteoglycans." Int Immunopharmacol 6(8): 1287-1297.

17. Gunde-Cimerman N (1999) “Medicinal Value of the Genus Pleurotus (Fr.) P.Karst. (Agaricaless.l., Basidiomycetes)." International Journal of Medicinal Mushrooms 1: 69-80.

18. Sudha G, Janardhanan A, Moorthy A, Chinnasamy M, Gunasekaran S, et al. (2016) "Comparative study on the antioxidant activity of methanolic and aqueous extracts from the fruiting bodies of an edible mushroom Pleurotusdjamor." Food Science and Biotechnology 25(2): 371-377.

19. Cabañero AI, Madrid Y, Cámara C (2006) "Selenium long-term administration and its effect on mercury toxicity" J Agric Food Chem 54(12): 4461-4468.

20. Jamwal A, Naderi M, Niyogi S (2016) "An in-vitro examination of selenium-cadmium antagonism using primary cultures of rainbow trout (Oncorhynchus mykiss) hepatocytes" Metallomics 8(2): 218-227.

21. Huerta VD, Sánchez MLF, Sanz-Mendel A (2005) "Qualitative and quantitative speciation analysis of water soluble selenium in three edible wild mushrooms species by liquid chromatography using postcolumn isotope dilution ICP-MS." Analytica Chimica Acta 538(1-2): 99-105.

22. da Silva MC, Naozuka J, Oliveira PV, Vanetti MC, Bazzolli DM (2010) “Invivo bioavailability of selenium in enriched Pleurotusostreatus mushrooms." Metallomics 2(2): 162-166.

23. Singh VK, Singh MP (2014) "Bioremediation of vegetable and agrowastes by Pleurotusostreatus: a novel strategy to produce edible mushroom with enhanced yield and nutrition". Cell Mol Biol (Noisy-legrand) 60(5): 2-6.

24. Vimala R, Das NJ (2009) "Biosorption of cadmium (II) and lead (II) from aqueous solutions using mushrooms: A comparative study." Journal of Hazardous Materials 168(1): 376-382.

25. FalandyszJ (2017) “Mercury accumulation of three Lactarius mushroom species." Food Chem 214: 96-101.

26. Kalač P, Svoboda L (2000) "A review of trace element concentrations in edible mushrooms." Food Chemistry 69: 273-281. 
27. Serafín Muñoz AH, Wrobel K, Gutierrez Corona JF, et al. (2007) “The protective effect of selenium inorganic forms against cadmium and silver toxicity in mycelia of Pleurotusostreatus." Mycological Research 111(Pt5): 626-632.

28. Stefanović V, Trifković J, Djurdjić S, Vukojević V, Tešić Ž, et al. (2016) "Study of silver, selenium and arsenic concentration in wild edible mushroom Macrolepiota procera, health benefit and risk." Environmental Science and Pollution Research 23(21): 22084-22098.

29. Cabañero AI, Madrid Y, Cámara C (2005) Study of mercury-selenium interaction in chicken liver by size exclusion chromatography inductively coupled plasma mass spectrometry. Journal of Analytical Atomic Spectrometry 20(9): 847-855.

30. Cabañero AI, Madrid Y, Cámara C (2006) Selenium long-term administration and its effect on mercury toxicity. J Agric Food Chem 54(12): 4461-4468

31. Mounicou S, Shah M, Meija J, Caruso JA, Vonderheide AP, et al (2006) Localization and speciation of selenium and mercury in Brassica juncea-implications for Se-Hg antagonism. Journal of Analytical Atomic Spectrometry 21(4): 404-412.

32. Yathavakilla SKV, Caruso JA (2007) A study of Se-Hg antagonism in Glycine max (soybean) roots by size exclusion and reversed phase HPLC-ICPMS. Anal Bioanal Chem 389(3): 715-723.

33. Wang A, Barber D, Pfeiffer C J (2001) Protective effects of selenium against mercury toxicity in cultured atlantic spotted dolphin (Stenellaplagiodon) renal cells. Arch Environ Contam Toxicol 41(4): 403-409.

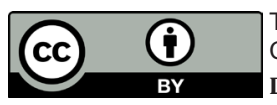

This work is licensed under Creative Commons Attribution 4.0 License DOI: $10.19080 /$ NFSIJ.2018.04.555640
34. Shanker K, Mishra S, Srivastava S, Srivastava R, Daas S, et al. (1996) Effect of selenite and selenate on plant uptake and translocation of mercury by tomato (Lycopersicumesculentum). Plant Soil 183(2): 233-238.

35. Shanker K, Mishra S, Srivastava S, Srivastava R, Dass S, et al. (1996) "Study of mercury-selenium (HgSe) interactions and their impact on Hg uptake by the radish (Raphanus sativus) plant." Food Chem Toxicol 34(9): 883-886.

36. Yang DY, Chen YW, Gunne JM, Belzile N (2008) "Selenium and mercury in organisms: Interactions and mechanisms." Environmental Reviews 16(NA): 71-92.

37. Gailer J (2007) "Arsenic-selenium and mercury-selenium bonds in biology." Coordination Chemistry Reviews 251: 234-254.

38. He PP, LV XZ, Wang GY (2004) "Effects of Se and Zn supplementation on the antagonism against $\mathrm{Pb}$ and $\mathrm{Cd}$ in vegetables."|Environ Int 30(2): 167-172.

39. Templeton DM, Ariese F, Cornelis R, Danielsson G, Muntaiu H, et al. (2000) "Guidelines for terms related to chemical speciation and fractionation of elements. Definitions, structural aspects, and methodological approaches (IUPAC Recommendations 2000)." Pure and Applied Chemistry 72(8): 1453-1470.

40. Cornelis R, Caruso JA, Crews H, Heumann K (2003) Handbook of elemental speciation: techniques and methodology. John Wiley, Chichester, USA, pp. 670.

41. Sgarbieri VC, Pacheco MTB (1999) "Revisão: Alimentos Funcionais Fisiológicos." Brazilian Journal of Food Technology 21(12): 7-19.

\section{Your next submission with Juniper Publishers will reach you the below assets}

- Quality Editorial service

- Swift Peer Review

- Reprints availability

- E-prints Service

- Manuscript Podcast for convenient understanding

- Global attainment for your research

- Manuscript accessibility in different formats

( Pdf, E-pub, Full Text, Audio)

- Unceasing customer service

Track the below URL for one-step submission

https://juniperpublishers.com/online-submission.php 